\title{
Sarcopenia: etiology, clinical consequences, intervention, and assessment
}

\author{
T. Lang $\cdot$ T. Streeper $\cdot$ P. Cawthon $\cdot$ K. Baldwin • \\ D. R. Taaffe • T. B. Harris
}

Received: 25 April 2009/Accepted: 18 August 2009/Published online: 25 September 2009

(C) The Author(s) 2009. This article is published with open access at Springerlink.com

\begin{abstract}
The aging process is associated with loss of muscle mass and strength and decline in physical functioning. The term sarcopenia is primarily defined as low level of muscle mass resulting from age-related muscle loss, but its definition is often broadened to include the underlying cellular processes involved in skeletal muscle loss as well as their clinical manifestations. The underlying cellular changes involve weakening of factors promoting muscle anabolism and
\end{abstract}

T. Lang $(\bowtie)$

Department of Radiology and Biomedical Imaging, UCSF/UCB Joint Bioengineering Graduate Group, University of California, UCSF/Center for Molecular and Functional Imaging,

185 Berry Street, Suite 350,

San Francisco, CA 94143-0946, USA

e-mail: thomas.lang@radiology.ucsf.edu

\section{T. Streeper}

Department of Radiology and Biomedical Imaging, University of California,

UCSF/Center for Molecular and Functional Imaging,

185 Berry Street, Suite 350,

San Francisco, CA 94143-0946, USA

P. Cawthon

California Pacific Medical Center Research Institute,

San Francisco, CA, USA

K. Baldwin

Physiology and Biophysics, University of California,

Irvine, CA, USA

D. R. Taaffe

School of Human Movement Studies,

The University of Queensland,

Brisbane, Australia

T. B. Harris

Laboratory of Epidemiology and Biometry,

Intramural Research Program, National Institute on Aging,

Bethesda, MD, USA increased expression of inflammatory factors and other agents which contribute to skeletal muscle catabolism. At the cellular level, these molecular processes are manifested in a loss of muscle fiber cross-sectional area, loss of innervation, and adaptive changes in the proportions of slow and fast motor units in muscle tissue. Ultimately, these alterations translate to bulk changes in muscle mass, strength, and function which lead to reduced physical performance, disability, increased risk of fall-related injury, and, often, frailty. In this review, we summarize current understanding of the mechanisms underlying sarcopenia and age-related changes in muscle tissue morphology and function. We also discuss the resulting longterm outcomes in terms of loss of function, which causes increased risk of musculoskeletal injuries and other morbidities, leading to frailty and loss of independence.

Keywords Aging · Falls · Imaging · Muscle strength . Sarcopenia $\cdot$ Skeletal muscle

\section{Introduction}

Skeletal muscle contractions power human body movements and are essential to maintaining stability. Skeletal muscle tissue accounts for almost half of the human body mass and, in addition to its power generation role, is a crucial factor in maintaining homeostasis of glucose metabolism. Given its central role in human mobility and metabolic function, any deterioration in the contractile, material, and metabolic properties of skeletal muscle has an extremely important effect on human health. Because the population in the USA aged 65 and over is expected to approximately double over the next 15 years [1], agerelated losses in skeletal muscle mass and function present an extremely important current and future public health 
issue. Loss of mobility, one of the major consequences of age-related skeletal muscle deterioration, is one of the primary determinants of the need for nursing home care, a public health cost which the US Health Care Finance Administration predicts may exceed 183 million dollars by 2010 [2]. The term coined by I.H. Rosenberg, which is widely used to describe skeletal muscle loss, is sarcopenia, from the Greek roots sarx (flesh) and penia (loss). Although this term is clinically applied to denote loss of muscle mass, it is often used to describe both a set of cellular processes (denervation, mitochondrial dysfunction, inflammatory and hormonal changes) and a set of outcomes such as decreased muscle strength, decreased mobility and function, increased fatigue, increased risk of metabolic disorders, and increased risk of falls and skeletal fractures. In this review, we (1) summarize current understanding of the mechanisms which underlie sarcopenia, (2) relate this information to age-related changes in muscle tissue morphology and function, and (3) describe the resulting longterm outcomes in terms of loss of function, which cause increased risk of musculoskeletal injuries and other morbidities, finally leading to frailty and loss of independence.

\section{Muscle fiber structure and the neuromuscular junction}

This section is derived from a number of excellent reviews of muscle cell structure and function [3, 4]. All of the body's skeletal muscles are composed of multinucleated cells called fibers. Each fiber incorporates the contractile proteins myosin and actin, along with numerous other regulatory proteins, which are organized into thick and thin filaments, respectively. The myosin and actin filaments are arranged in periodic bands within structures called sarcomeres, and a repeated sequence of sarcomeres form tubelike structures called myofibrils. Each muscle fiber contains a large number of parallel myofibrils, and the force generated by the muscle fiber is proportional to the number of myofibrils it contains. Muscles are innervated by motor neurons. In the case of small muscles used for fine motor control, motor neurons may innervate only a few small fibers. In larger muscles, a fiber is innervated by a single branch of a motor neuron, and the motor neuron innervates many muscle fibers. The combination of a single motor neuron and the muscle fibers innervated by its branches is called a motor unit. The hierarchic organization of muscle tissue is diagrammed in Fig. 1.

A skeletal muscle motor unit is activated when a signal is generated in the motor cortex of the brain, traveling though the spinal cord, and is transmitted as an action potential through the motor neurons to each fiber in the motor unit, resulting in a simultaneous contraction of the fibers. When the nerve impulse reaches the junction between the motor neuron branch and the fiber, acetylcholine is released from the axon end of the neuron. A wave of electrical changes are produced in the muscle cell when the acetylcholine binds to receptors on the fiber cell surface, causing release of calcium from the sarcoplasmic reticulum, which activates the contractile machinery to generate power.

The power generated in a muscle contraction is provided by the interaction of the actin and myosin components within the sarcomere. In the broadest terms, this occurs when the myosin component attaches to the actin framework. Following a sequence of chemical transformations via actin-induced breakdown of adenosine triphosphate (ATP), free energy is released to generate both force production and movement of actin within the sarcomere, thereby causing the whole muscle to generate force and movement. Several reviews describing this process are provided in the following references [5-12].

Motor units are differentiated into three main types based on the specific type of myosin expressed in the fibers. Slow motor units contain the smallest number of fibers and consist of type 1 myosin, which transduces energy at a relatively slow rate. Thus, these fibers/motor units contract with relatively slow velocity. Type I fibers in slow motor units are especially rich in mitochondria and myoglobin, which make them reddish in color and which allow for a high capacity for sustained delivery of ATP from oxidative metabolism of triglycerides and carbohydrate. The oxidative ATP synthesis process characteristic of type I fibers is relatively slow to ramp up and can be sustained for long periods of time, making these motors units well-suited for sustained aerobic exercise such as distance running. Additionally, the low contraction velocity means that these slow motor units are also heavily recruited in precise finite motor activities and in opposing gravity. Fast fatigable motor units generate more force and have higher velocities than slow motor units, both because they have the highest number of fibers and because the individual fibers have the largest cross-sectional area (CSA) and the highest contractile velocity. These motor units express type IIx myosin, which transduces energy at a faster rate than type I myosin. These fibers are relatively poor in mitochondria, and the primary source of ATP is through glycolysis of glycogen, which can provide considerable energy over a relatively short time period. Fast fatigable motor units are typically recruited during activities such as weightlifting or sprinting, which require maximal power generation. In addition, there is a third type of motor unit, the fast fatigue-resistant motor unit, which transduces energy at a rate which is intermediate between slow and fast fatigable motor units. Fast fatigue-resistant motor units contain type IIa myosin and are intermediate in CSA between type I and type IIx and are also intermediate in 


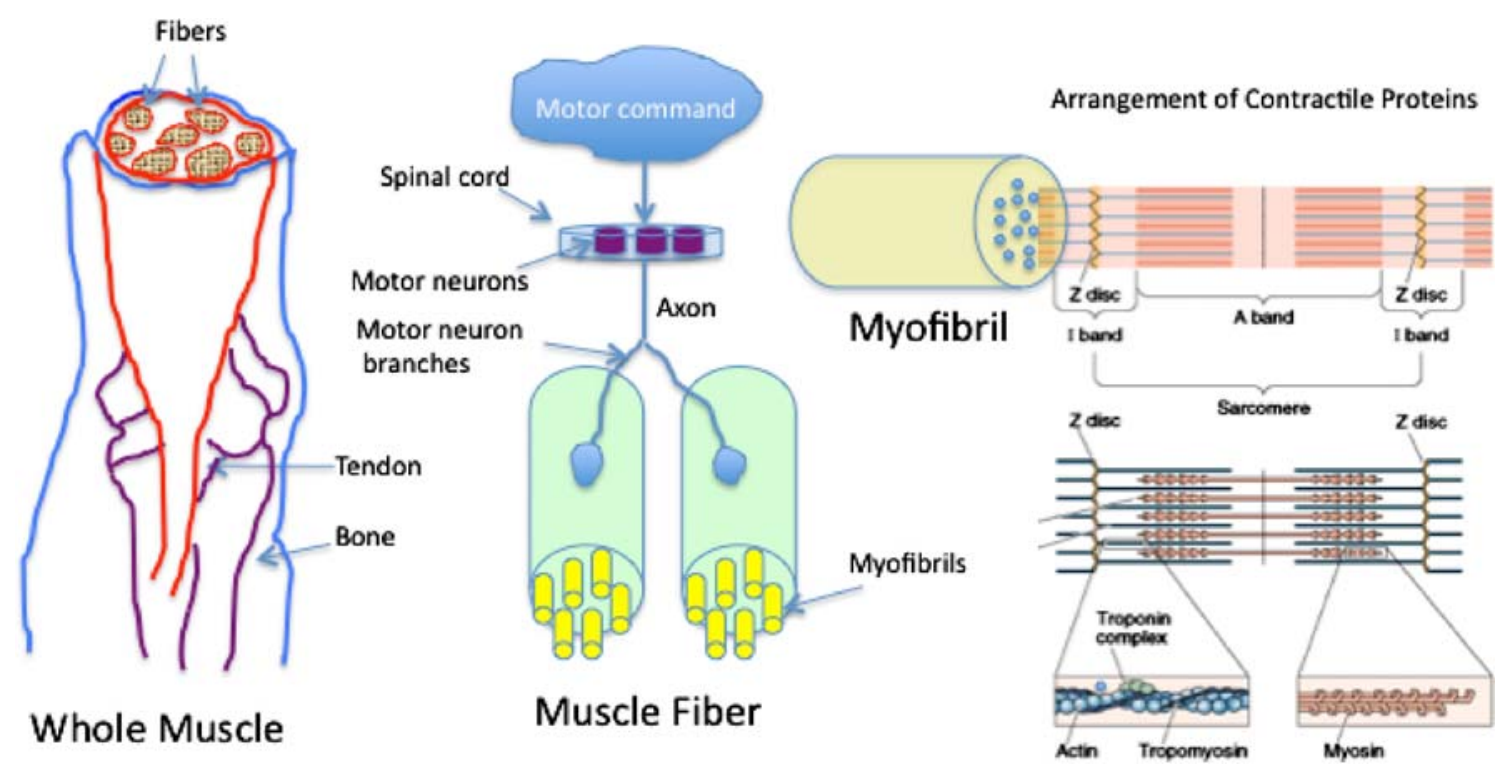

Fig. 1 Hierarchical depiction of skeletal muscle structure, depicting the skeletal muscle fibers within the muscle bundle, a motor unit branching out to two muscle fibers and the detailed structure of myofibrils

terms of the number of fibers and in velocity of contraction. Contractile force, normalized by CSA, is similar across fiber types, but the maximum power, normalized for fiber CSA, of the fast fatigable motor units is at least four times greater due to the higher contractile velocity compared to the slow type I motor units.

\section{Age-related changes in muscle contractile properties}

The term "sarcopenia" has been employed to describe the loss of muscle tissue that occurs over a lifetime and is also commonly used to describe its clinical manifestation as well. Age-associated processes bring about changes in the mass, composition, contractile properties, and material properties of muscle tissue, as well as in the function of tendons. These changes translate to alterations in muscle power, strength, and function, leading to reduced physical performance, disability, increased risk of fall-related injury, and, often, frailty. This section will provide a brief review of some of the age-related changes that affect the contractile and material properties of muscle as well as the function of tendons.

Age-related changes in muscle morphology

The age-related loss of muscle mass results from loss of both slow and fast motor units, with an accelerated loss of fast motor units. In addition to the loss of fast motor units, there appears to be fiber atrophy, or loss of CSA, of type II fast glycolytic fibers $[13,14]$. As motor units are lost via denervation, an increased burden of work is transferred to surviving motor units, and as a potential adaptive response, remaining motor units recruit denervated fibers, changing their fiber type to that of the motor unit. Thus, there is a net conversion of type II fibers to type I fibers, as the type II fibers are recruited into slow motor units (Fig. 2). As a result, although there is relatively little change in the average CSA of type I fibers, the percentage of the total muscle cross-sectional area occupied by type I fibers tends to increase with age, whereas not only are type II fibers lost but the CSA and the aggregate power-generating capacity of the remaining fibers also decrease dramatically. Finally, while in young muscle tissue there is a mosaic-like appearance corresponding to presence of both types of fibers, in aged muscle, the recruitment of denervated fibers by surviving motor units causes a clustering of similar fiber types [13, 14].

The loss of both type I and accelerated loss of type II fibers results in sharp age-related changes in muscle function. The loss of fast motor units and the concomitant loss of type II fibers result in loss in muscle power necessary for actions such as rising from a chair, climbing steps, or regaining posture after a perturbation of balance. The extent of skeletal muscle power loss with age has been confirmed by studies of cycle ergometry in which the cycle velocity at maximal power was measured. In a study of human volunteers ranging in age from 20 to 90 years, Kostka et al. found that velocity at maximal power decreased by roughly $18 \%$ between ages $20-29$ and 50 59 and by a further $20 \%$ between $60-69$ and $80-89$ [15]. In addition to studies examining muscle power and contrac- 
Fig. 2 Effect of age on the motor unit, depicting, young, aged, and aged sarcopenic fibers. This drawing depicts the pronounced denervation of type II fibers and the recruitment of type I fibers into surviving motor units in older subjects, with impairment of recruitment in sarcopenic subjects

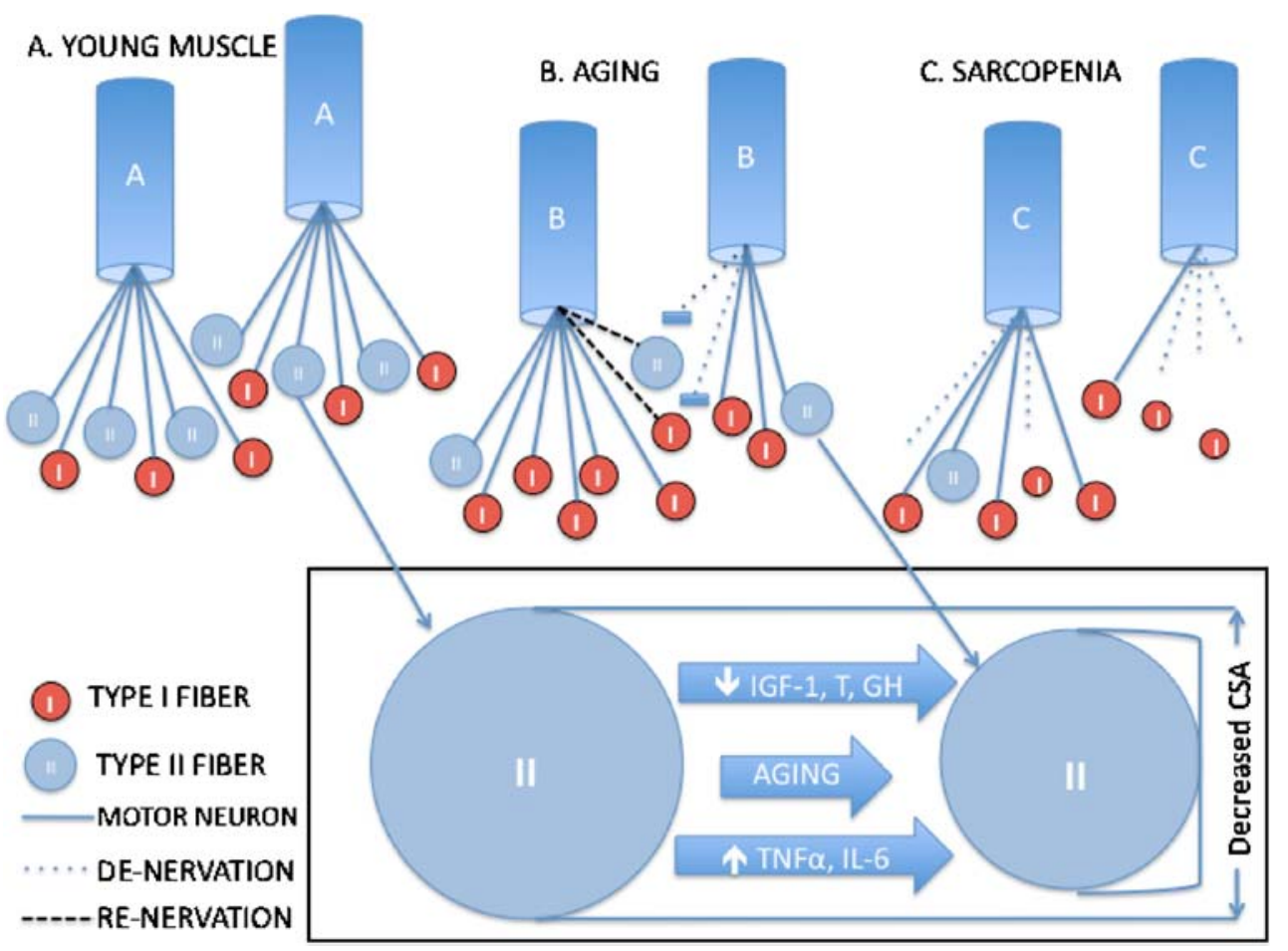

tion velocities, other studies have cross-sectionally examined age-related changes in strength, showing strength declines as great as 30-35\% [16]. These alterations in strength have been linked primarily to declines in muscle mass as well as reductions in power per unit area and force per unit area, as nonmuscle tissue components replace lost muscle fiber [17].

Another morphologic aspect of aging skeletal muscle is the infiltration of muscle tissue components by lipid, which can be contained within adipocytes as well as deposited within muscle fiber. The aging process is thought to result in increased frequency of adipocytes within muscle tissue. As with precursor cells in bone marrow, liver, and kidney, muscle satellite cells can express both adipocytic and a myocytic phenotypes, and recent studies have reported that expression of the adipocytic phenotype is increased with age [18-21]. This process is still relatively poorly understood in terms of its extent and spatial distribution. Another well-known source of adiposity in muscle tissue is through increased deposition of lipid within muscle fibers [22-28]. This type of lipid distribution, often referred to as intramyocellular lipid, may result from net buildup of lipid due to reduced oxidative capacity of muscle fibers with aging $[22,29]$.

Neurologic underpinnings of muscle atrophy

The correct functioning of motor neurons is essential to the survival of muscle fibers. Age-related neurodegeneration may contribute importantly to the effects of age on muscle structure, including loss of muscle fibers, atrophy of muscle fibers, and increased clustering of muscle fibers as denervated fibers are recruited into viable motor units. Multiple levels of the nervous system are affected by age, including the motor cortex (beyond the scope of this review), the spinal cord, peripheral neurons, and the neuromuscular junction. Within the spinal cord, there is a substantial decline in the number of alpha motor neurons, and there may be a preferential loss in those motor neurons supplying fast motor units. Other reports have noted agerelated losses in peripheral nerve fibers and alterations of their myelin sheaths. Finally, age-related changes have been noted in the neuromuscular junction, with reduced number [30] but increased size of terminal areas and a reduction in the number of synaptic vesicles [31]. Others have noted increases in the amount of neurotransmitters released in nerve impulses and increased sprouting and branching of terminal axons, all of which may serve as an adaptive mechanism underlying the ability of viable motor units to recruit denervated muscle fibers [32].

Key factors in age-related changes in protein balance

Skeletal muscle is characterized by a dynamic balance between the synthesis of protein from free amino acids in the cellular milieu and the dissociation of muscle protein into free amino acids. Maintenance of muscle mass requires that the rate of synthesis be in balance with the rate of degradation; over time, deficits can result in severe muscle loss. Aging is associated with decreased expression of hormonal factors that 
promote protein synthesis and increased expression of both endocrine and inflammatory factors that contribute negatively to protein balance by increasing protein degradation. Figure 3 summarizes the role of endocrine, inflammatory, and other factors in protein synthesis.

$I G F-1$

Insulin-like growth factor 1 (IGF-1) is a well-known promoter of protein synthesis in skeletal muscle. Skeletal muscle fibers have a set of transmembrane receptors that bind insulin and IGF-1 to regulate proliferation, differentiation, and fusion of skeletal muscle precursor cells [33]. There are two primary sources of IGF-1. Mature IGF-1 is produced systemically by the interaction of growth hormone $(\mathrm{GH})$ with the liver. The other source of IGF-1 is within the skeletal muscle itself, with two primary variants [34], including one which is produced in response to physical activity and is referred to as mechano growth factor and one which is similar to the mature IGF-1 produced within the liver [35, 36]. IGF-1 binds to receptors on skeletal muscle cell surfaces and activates a complex array of cell signaling pathways which are anabolic, anticatabolic, and antiapoptotic [37]. This age-related decline stems both from the decline of growth hormone, which results in reduced liver IGF-1 production as well as a reduction in the ability of skeletal muscle cells to produce IGF-1 locally. Therefore, the age-related decline in IGF-1 production is linked to age-related reductions in protein synthesis and muscle cell function. Finally, loss of IGF-1 may also compromise motor neuron function in aging. IGF1 overexpression in transgenic mice has been reported to protect against age-related changes in the neuromuscular junction [38], and in other reports IGF-1 was found to be instrumental in transforming nerve action potential to the release of calcium ion from the sarcoplasmic reticulum [39].

\section{Age-related changes in inflammatory factors}

In chronic inflammatory diseases associated with muscle atrophy, such as cancer cachexia and autoimmune disorders, muscle cell protein degradation is accelerated, and muscle protein synthesis appears to be diminished [40, 41]. The ubiquitin-proteasome pathway is the most important mechanism for protein degradation in skeletal muscle cells. This system involves a series of enzymatic steps in which the degraded proteins are first targeted by an enzyme system that binds the target protein to the polypeptide ubiquitin. These ubiquitinized proteins are then transferred to the proteasome complex and degraded into short peptides and are finally recycled as free intracellular amino acids [42]. This pathway is promoted by inflammatory cytokines such as tumor necrosis factor alpha (TNF- $\alpha$ ) and interleukin 6 (IL-6), by hormones such as cortisol and angiotensin, as well as by reactive oxygen species.

Increased expression of these inflammatory cytokines also appears to be common in aging in skeletal muscle.
Fig. 3 Age effects on systemic factors influencing synthesis and degradation of skeletal muscle proteins

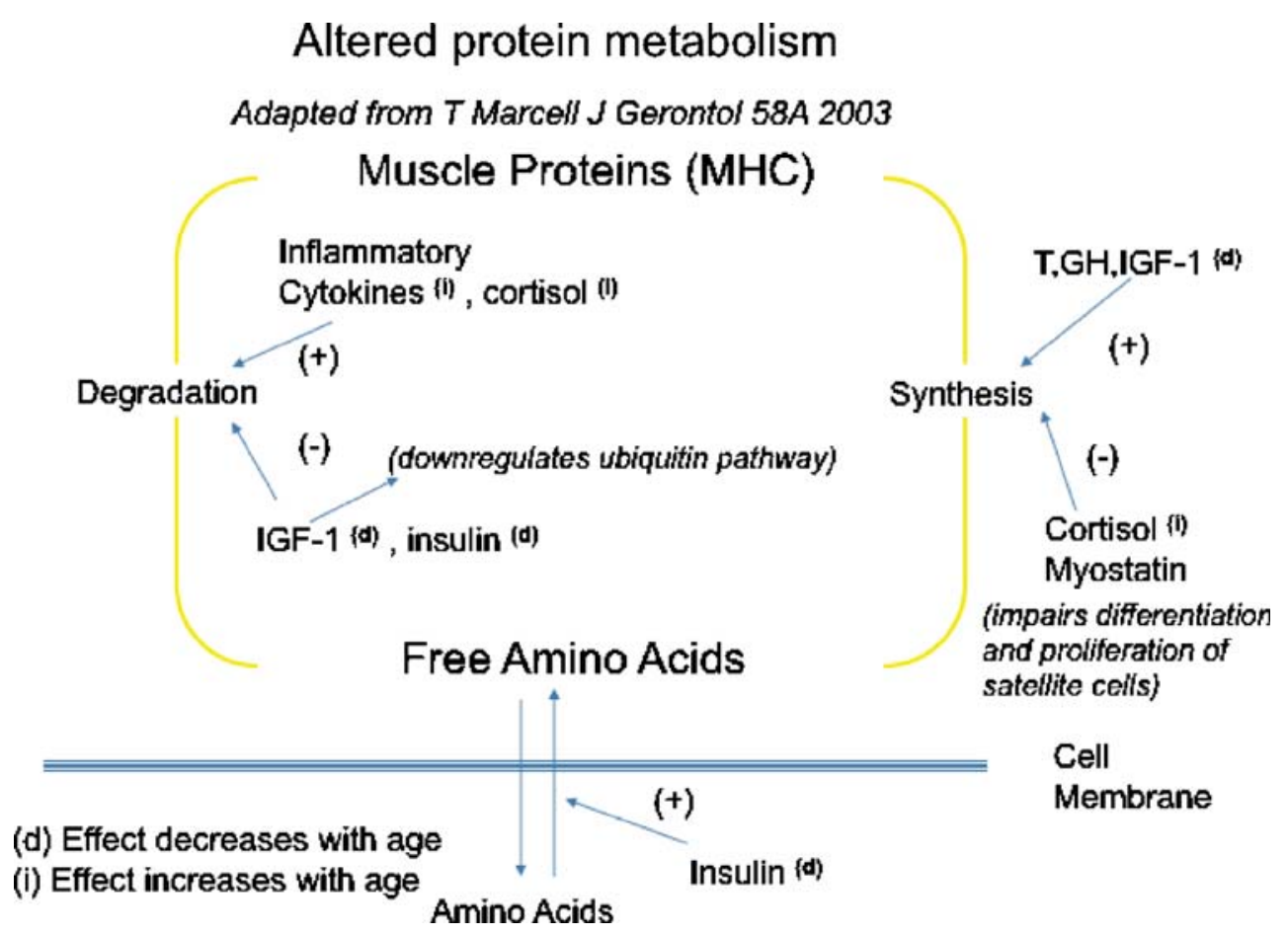


Comparison of skeletal muscle biopsies from younger and older subjects showed increased expression of genes upregulated by inflammatory factors [43]. Levels of catabolism-inducing hormones such as cortisol have also been shown to increase with age, and cortisol is linked to increased expression of IL- 6 and TNF- $\alpha$. Increased TNF- $\alpha$ expression is also known to stimulate muscle atrophy through apoptosis. Apoptosis contributes to the loss of myonuclei in skeletal muscle cells and could theoretically result in the loss of complete fibers in sarcopenia [44].

\section{Oxidative damage}

Oxidative metabolism generates reactive oxygen species (ROS), and these metabolic products are thought to accumulate over time, altering and damaging cell components, particularly mitochondria and DNA sequences [45]. Because mitochondria produce ROS, they are subject to alterations in their structure and in their DNA. Alterations to mtDNA are known to increase with age in skeletal muscle, and the frequency of abnormal mitochondrial regions is higher in those muscles which are strongly affected by sarcopenia [45-47]. The role of mitochondrial DNA alterations in age-related loss of skeletal muscle function is under intense investigation, focusing on their roles in causing skeletal muscle cell apoptosis and structural abnormalities that affect metabolic function. Structural alterations to mitochondria may affect the electron transport chain, compromising respiration. Although the loss of maximal oxygen consumption $\left(\mathrm{VO}_{2}\right.$ max) with age has been primarily attributed to loss of muscle mass and reduced cardiac output, altered mitochondrial metabolism, leading to poorer muscle cell respiration, may also be involved.

\section{Intrinsic changes to skeletal muscle}

One potential mechanism for sarcopenia involves the loss of muscle regenerative capacity due to loss in the number and function of muscle satellite cells, which proliferate and differentiate into skeletal muscle fibers. Some studies have observed declines in the numbers of muscle satellite cells in both rodents and humans [48], with others reporting that this decline was larger in muscles containing primarily type II fibers than in those containing type 1 fibers [49]. However, other studies have failed to observe a change in satellite cell number with age, and others have even reported slight increases [50]. There is some evidence that failure of muscle tissue to regenerate may involve agerelated changes in the molecular regulators, called myogenic regulatory factors (MRF) of muscle satellite cell proliferation and differentiation, rather than in the number of satellite cells. In general, studies that have compared the expression of MRFs such as myogenic determination factor (myoD), myogenic regulatory factor 5 , and myogenin in rats have found that expression of these factors is decreased in older compared to younger skeletal muscle [51]. Human studies have shown impaired differentiation of myoblasts, which has been associated with reduced or delayed expression of these factors [52]. Another factor in the behavior of muscle satellite cells is myostatin, which is thought to suppress differentiation and proliferation of myocytes by suppressing the expression of MRFs such as myoD and myogenin [53]. While there is considerable work which has demonstrated that myostatin suppression may have therapeutic potential for combating muscle wasting, the effect of age on myostatin expression is still under active investigation. Some investigations using rat models have found that myostatin mRNA levels have remained constant with age [54], while others observed age-related increases [55]. With respect to studies in human models of muscle wasting, there is similar variance in findings, with one cross-sectional study reporting no change in myostatin expression in the vastus lateralis muscle between young and older men [56], while a similar study in women found a $56 \%$ increase in myostatin expression in the vastus lateralis [57]. Thus, while myostatin is an important target in combating muscle wasting, the role of age-related changes in myostatin expression is still a controversial subject.

\section{Age-related changes in the stiffness of the muscle-tendon system}

When considering age-related losses in performance, it is important to take into account that muscle and tendons act as a unit. Human motion requires the transmission of contractile forces generated in skeletal muscle tissue through the tendons to the skeleton. Thus, age-related alterations in mobility are not only a function of changing skeletal muscle contractile properties but also of the mechanical properties of the tendons which operate in series with the muscle. A loss in tendon stiffness with age, for example, would reduce the rate of force development caused by skeletal muscle contraction, whereas increased tendon stiffness with age would tend to counteract the agerelated decrease in skeletal muscle contractile function.

Animal studies of age effects on tendon mechanical properties have yielded variable results, with some studies showing increased stiffness with age [58], while other studies have shown decreased stiffness with age $[59,60]$ or little to no effect of age on tendon stiffness [61]. Narici et al. have pointed out that some of this variability may be attributable to differences in the age range between animal groups as well as due to measurement artifacts associated 
with clamping of the excised tendons [62]. Human studies of tendon properties have until recently been hindered by requirements for cadaver donors and have been somewhat scarce. To study tendon properties in vivo, a technique has been developed based on longitudinal measurement of tendon deformation by imaging ultrasound during an isometric muscle contraction [63]. Initial studies using this technique compared young and elderly groups, observing that tendons from older subjects were on the order of $15 \%$ more compliant [62]. The observation that the tendons from the young and older subjects had approximately similar dimensions supported the idea that the observed differences could be attributed to differences in mechanical properties. In addition to the observation that older tendons have lower stiffness than tendons from younger subjects, there is also evidence that tendon stiffness can be increased through exercise training [64]. The ability to increase the stiffness of tendons would improve mobility by allowing for faster generation of force on bone, reducing the power and metabolic requirements on skeletal muscle tissue. Narici et al. have presented excellent reviews of the literature on age-related changes in human tendon mechanical properties $[62,65]$.

\section{Clinical manifestations of sarcopenia}

With aging, multiple processes occurring within muscle tissue, such as denervation, changes in the hormonal and inflammatory environment, mitochondrial dysfunction, and changes in the expression of regulatory factors affecting the fate of satellite cells, combine to produce losses in the bulk properties of muscle tissue such as muscle mass and strength. Among the elderly, these changes may eventually result in loss of mobility and independence and increased risk of injury.

\section{Loss of muscle power}

Age-related loss of skeletal muscle contractile power, which is essential to human motions such as rising from a chair or climbing a flight of stairs, is one of the clinical consequences most commonly linked with sarcopenia. The decline in muscle power has been established in both genders, under multiple loading conditions, in multiple limbs, and in both cross-sectional and longitudinal studies [17]. The most important anatomic sites for muscle function measurement have primarily been in the lower body, as the muscles in these sites are critical for daily function and allow for closest comparison to biopsy data. Further, power and strength losses in the lower limbs confer the largest risk factors for falls and other sources of injury and disability $[66,67]$. Lower-limb power and strength are often measured using knee extension and flexion. Measurements can be isotonic, changing the length of the muscle fibers against constant resistance, isokinetic, in which fibers are shortened or lengthened at fixed velocity, or isometric, in which fiber length remains constant in the presence of a force greater than the muscle is capable of counteracting. Isokinetic and isotonic measurements of knee extension and flexion, in that they involve translating a weight along an arc of motion within a given time interval, are measures of muscle power (although they are mostly reported as joint torques in feet pounds or Newton meters) whereas isometric measurements involve purely the ability to generate force. Because these loading conditions are more relevant to human motion, most studies have reported results of isokinetic and isotonic exercise. Table 1 summarizes results of cross-sectional studies of lower-extremity muscle function [68-73]. In cross-sectional studies comparing young normal subjects in the 20-40-year age range to healthy elders in the 70-80-year age range, declines in knee extensor torque and power have ranged from $20 \%$ to $40 \%$, with greater losses in the $50 \%$ range reported for individuals in their 1990s [74-78]. Over the lifetime, men have inherently greater knee extensor power and torque than women, but on a percentage basis, age-related losses are similar between genders, with losses in men incurring greater absolute losses because they start with higher baseline values. Compared to the abundance of crosssectional studies, there are fewer longitudinal studies of knee extensor properties with aging. Hughes et al. examined a cohort of 52 elderly men and 68 women who had been examined 10 years earlier, finding similar declines in the knee extensors and flexors ranging from $12 \%$ to $18 \%$ per decade [79]. Longitudinal studies of smaller cohorts have shown variable results, with one study reporting losses of roughly $3 \%$ per year in 23 men aged $73-86$ at baseline [80], and another study which reported no changes in strength of either men or women over an 8-year follow-up [81]. Cross-sectional studies of isometric measurements of ankle plantar flexion have shown age-related declines similar to those measured for knee extension torque and power. Studies of age-related muscle strength in the upper extremities show essentially similar results to the lower extremities, with cross-sectional studies reporting declines of $20-40 \%$ in measures such as hand-grip strength and elbow extension torque between healthy younger subjects and elderly subjects and longitudinal studies showing yearly declines ranging from $1 \%$ to $5 \%$ [17].

Loss of skeletal muscle mass

Loss of skeletal muscle mass with age has been documented by lean body mass measurements with dual X-ray absorptiometry (DXA) and with muscle cross-sectional areas quantified by three-dimensional imaging methods 
Table 1 Age-related changes in muscle power and muscle strength

\begin{tabular}{|c|c|c|c|c|c|}
\hline Study & Gender & Measurement/joint/movement & Age range (years) & Study design & Changes with aging ${ }^{\mathrm{a}}$ \\
\hline Dean et al. 2004 [73] & $\mathrm{F}$ & IK/hip/FLX, EXT & $21-82$ & $\mathrm{CS}$ & $\downarrow 22-33 \%$ \\
\hline Johnson et al. 2004 [72] & $\mathrm{F}$ & $\mathrm{IK}, \mathrm{IM} / \mathrm{hip} / \mathrm{AD}, \mathrm{AB}$ & $21-91$ & $\mathrm{CS}$ & $\downarrow 24-34 \%$ IK,$\downarrow 44-56 \%$ IM \\
\hline Kubo et al. 2007 [71] & M & IM/ankle/PF & $20-77$ & $\mathrm{CS}$ & $\downarrow 40 \%$ \\
\hline Morse et al. 2005 [70] & M & IM/ankle/PF & $25.3 \pm 3.5-73.8 \pm 3.5$ & $\mathrm{CS}$ & $\downarrow 47 \%$ \\
\hline Petrella et al. 2005 [69] & $\mathrm{M}, \mathrm{F}$ & IT/knee/EXT & $20-75$ & $\mathrm{CS}$ & $\downarrow 41-137 \%$ \\
\hline Lanza et al. 2003 [68] & M & IT, IM/knee, ankle/EXT, DF & $20-85$ & $\mathrm{CS}$ & $\downarrow 26-32 \%$ \\
\hline
\end{tabular}

$K$ isokinetic, $I M$ isometric, $I T$ isotonic, $F L X$ flexion, $E X T$ extension, $A D$ adduction, $A B$ abduction, $P F$ plantar flexion; $D F$ dorsiflexion, $C S$ crosssectional

${ }^{a}$ Expressed as percent change with aging

such as X-ray computed tomography (CT) or with magnetic resonance imaging (MRI). Leg lean tissue mass by DXA, a marker for skeletal muscle mass, decreases by roughly $1 \%$ per year in longitudinal studies [17], a value roughly threefold smaller than the loss of skeletal muscle strength. Studies which assess muscle mass through CSA measurement have found that CSA decreases by roughly $40 \%$ between 20 and 60 years, with the reported amount varying with imaging technique, skeletal site, and gender $[9,16]$. Measurements of the CSA of the quadriceps muscle using CT have shown decrements of around $25-35 \%$ between older subjects and young normal controls [82]. Large crosssectional studies including both older men and women have found that men, on average, have larger muscle mass and cross-sectional area values than women but that the largest cross-sectional age-related changes occurred in men. This potential gender difference in age-related loss of muscle mass may reflect differences in the pattern of age-related changes in testosterone, growth hormone, and IGF-1 [17].

Risk factors conferred by decrements in muscle power and mass

Prospective cohort studies have demonstrated the association of age-related loss of muscle strength and mass with adverse clinical outcomes in the older population, including falls, mobility limitations, incident disability, and fractures [66, 67, 83]. Moreland et al. have carried out a metaanalysis summarizing the relation of upper- and lower-body weakness to falls [67]. Measures of lower-body weakness, defined as increased chair stand time and reduced knee extension strength, have been correlated to incidence of any fall with odds ratios ranging from 1.2 to 2.5 , to injurious falls with odds ratios around 1.5 , and to recurrent falls with much higher odds ratios, ranging from 2.2 to 9.9. Upperbody weakness, which is typically assessed using hand-grip strength or manual muscle testing, is also correlated to fall incidence, with odds ratios for incident falls ranging from 1.2 to 2.3 and for recurrent falls with odds ratios of 1.4-1.7.
Clearly, lower-extremity weakness is a better predictor of falls than weakness of the upper body. Other studies have explored the mechanisms by which impaired muscle strength relates to falls by analyzing the effect of muscle strength in single-step recovery from a forward fall [8487]. This may be simulated by leaning subjects forward and then releasing them, measuring muscle activation, joint kinetics, and other characteristics as the subjects step forward after release. Multiple studies have found that older individuals have discernible differences in these measurements. Thelen et al. compared muscle activities in young and elderly subjects and found that the latter showed delays in activating the hip flexors and knee extensors during the period in which the stepping leg is swung into position $[84,85]$. Wojcik et al. found that elderly adults generate lower hip flexion and extension torques than young adults during single-step recoveries after being placed at a forward lean angle [86, 87]. Thus, there is evidence that reduced strength of the hip and other lowerleg muscles, in addition to impaired neuromuscular activation, may be implicated in poor recovery from falls. In addition to falls, muscle weakness and reduced muscle mass have been associated with incident disability. The Health, Aging, and Body Composition Study investigators carried out studies of body composition, muscle strength, and other risk factors on incident mobility limitation, defined as inability to walk a quarter mile or climb a flight of ten stairs. Visser et al. observed that low-thigh muscle CSA measured at baseline resulted in a $45 \%$ and $34 \%$ increased risk of mobility limitations 5 years later in men and women, respectively [88]. For low-knee extensor power and torque, the risk of incident mobility limitation was even higher, at $66 \%$ and $69 \%$ for men and women, respectively [88]. The same study found that men and women in the lowest quartile of thigh muscle crosssectional area and leg muscle mass had a $30-40 \%$ increase of risk for the inability to carry out the activities of daily living. For major disability, which includes inability to carry out activities of daily living, inability to walk a 
quarter mile, or climb ten steps, low-thigh CSA increased risk by $40 \%$ whereas low-knee extensor strength resulted in over a doubling of the risk. These subjects were also followed up for incident hospitalizations, and low-thigh CSA and muscle strength showed a similar predictive power for this outcome. Thigh muscle cross-sectional area and knee extension torque have also been shown to correlate to incident hip fracture in the Health $\mathrm{ABC}$ study [89]. Lang et al. observed that knee extension torque and low cross-sectional area individually resulted in increased risk of incident hip fracture by $50-60 \%$, independent of bone mineral density (BMD).

The increased risk of mobility loss and injury resulting from loss of muscle mass and power are part of a vicious cycle which is amplified with age. In addition to reductions in performance, the intermediate consequences of muscle loss include reductions in metabolic rate and aerobic capacity. The loss of power and endurance increase the difficulties associated with procuring adequate nutrition and increase the effort required to undertake exercise. The combination of nutritional loss and reduced physical activity levels results in further loss of muscle mass and power, exacerbating the process of sarcopenia. The resulting decrements in power, endurance, and physical performance, if unchecked, then lead to a loss of independence which may or may not be preceded by injury or illness, for example a fall and/or fracture.

\section{Treatments for sarcopenia}

\section{Exercise}

Many studies have documented that exercise provides benefits extending across multiple physiological systems in the aged population. Resistive training, also known as weight or strength training, can be used to counteract age- related muscle loss by increasing the number and crosssectional areas of skeletal muscle fibers. Increases of $11.4 \%$ in midthigh muscle CSA and greater than $100 \%$ in knee extensor torque were reported by Frontera et al. in a cohort of elderly men who had undergone 12 weeks of highintensity resistance exercise training [90], with similar changes observed in a subsequent study in women by Charette and colleagues [91]. Moreover, resistance exercise even has benefits when it is not routinely performed. A recent study by Henwood and Taaffe documented that resistive exercise can produce sustained increases in knee extensor torque even after periods of deconditioning following cessation of exercise [92]. The benefits of resistive exercise have been shown to extend even to frail populations. Increases of 3-9\% in muscle CSA, doubling of muscle strength, and improvement in functional performance indices have been reported in nursing home populations after bouts of progressive resistance training $[93,94]$. Resistive exercise has been shown to be well tolerated in the elderly and is of value in the prevention of falls and loss of mobility. The time and equipment requirements to undertake a program of resistive exercise are modest, with sessions of $30 \mathrm{~min}$, twice per week, using either exercise machines or body weight and elastic bands. Finally, resistive exercise has been shown to result in improvement in a range of different clinical conditions common in elderly people, including osteoporosis, osteoarthritis, heart disease, diabetes, and depression. A summary of relevant literature on exercise and pharmacologic intervention in the elderly is presented in Table 2.

\section{Hormone replacement}

In elderly men, epidemiologic studies generally support a relationship between declines in testosterone levels with age and loss of muscle strength and functional status [95]. Menopause and age-related reduction of estrogen levels in

Table 2 Studies examining various interventions for age-related muscle loss

\begin{tabular}{lllllll}
\hline Study & Population & Gender & Age & N & Intervention & Findings \\
\hline Solerte et al. (2008) [149] & S & M, F & $66-84$ & 41 & AA supp. & $\uparrow$ Lean mass, $\uparrow$ IGF-1, $\downarrow$ TNF- $\alpha$ \\
Trappe et al. (2000) [150] & E & M & $74 \pm 2$ & 7 & RT & $\uparrow S ; \uparrow M H C$ I \\
Trappe et al. (2001) [151] & E & F & $74 \pm 2$ & 7 & RT & $\uparrow S$ \\
Slivka et al. (2008) [152] & E & M & $80-86$ & 6 & RT & $\uparrow S, \uparrow C S A$ \\
Fiatarone et al. (1990) [93] & E & M & $90 \pm 3$ & 10 & HIRT & $\uparrow S, \uparrow C S A$ \\
Kryger et al. (2007) [153] & E & M, F & $85-97$ & 11 & RT & $\uparrow S, \uparrow C S A$ \\
Frontera et al. (2003) [154] & E & F & $68-79$ & 14 & RT & $\uparrow S, \uparrow C S A$ \\
Wittert et al. (2003) [155] & E & M & $60-86$ & 76 & TE & $\leftrightarrow$ S, $\uparrow C S A$
\end{tabular}

$S$ sarcopenia, E elderly, Myo-29 a myostatin inhibiting drug, AA Supp amino acid supplement, RT resistance training, HIRT high-intensity resistance training, $T E$ testosterone, $S$ strength, $C S A$ muscle cross-sectional area, $I G F-1$ insulin-like growth factor $1, T N F-\alpha$ tumor necrosis factor alpha, $M H C I$, myosin heavy chain type I isoform 
women may also impact muscle strength because estrogen is converted to testosterone, which has an anabolic effect on muscle protein synthesis. Further, both sex hormones may suppress inflammatory cytokines that exert catabolic effects on muscle. Thus, hormone replacement has always received considerable interest as a therapy for sarcopenia. In women, trials of estrogen and testosterone therapy have failed to yield any meaningful increases of muscle strength [96]. Studies of testosterone replacement therapy in men has had mixed results, depending on age of the subjects. Several studies have shown that administration of testosterone in hypogonadal younger men produced significant increases in lean body mass and muscle strength [97-99]. Strength increases ranged from $20 \%$ to $60 \%$ but tended to be smaller than the increases produced by resistive exercise training. Anabolic effects of testosterone therapy on older hypogonadal men tend to be weaker, with most studies reporting minimal changes in body composition and no increases in muscle strength [96]. However, some studies have reported moderate strength improvements ranging from $10 \%$ to $25 \%$, but unlike the negative results, all of these trials lacked control groups. However, it should be noted that testosterone is administered to older men in much lower doses than to younger men because of increased risk of prostate cancer and other side effects [96].

Considerable interest has also been devoted to testing the effect of GH on sarcopenia. Growth hormone exerts an indirect anabolic effect on muscle by stimulating production of IGF-1 in the liver. Levels of growth hormone are systematically lower in the elderly, and thus it was hypothesized that $\mathrm{GH}$ would be effective in combating muscle loss in elderly subjects. However, most studies have shown that GH treatment is ineffective in the elderly, both from the standpoint of muscle mass and muscle strength. The failure of GH treatment to augment muscle strength in elderly subjects has led to other approaches, such as treatment with growth-hormone-releasing hormone, which was found to increase $\mathrm{GH}$ production and produce moderate increases in muscle strength [96-100]. Additionally, others have tried direct administration of IGF-1. By complexing IGF-1 to its primary circulating binding protein IGFBP-3, it is possible to significantly increase the IGF-1 dose while eliminating the side effect of hypoglycemia that occurs with IGF-1 alone [101]. Boonen et al. reported that administration of IGF-1/IGFBP-3 to elderly women with recent hip fracture was well tolerated and resulted in increased grip strength [102].

Newer pharmacologic approaches

Among the newer approaches evolving towards treatment of muscle wasting is inhibition of myostatin, which counteracts the myogenic regulatory factors which promote the differentiation and proliferation of myocytes. In animal studies, myostatin blockade using experimental agents and other approaches appears to produce increases in muscle mass and strength in rodent models [103-105]. Another approach involves administration of selective androgen receptor modulators (SARMs). These nonsteroidal agents target the androgen receptor, which is found in sexual organs, skeletal muscle, and bone but have less of a stimulative effect on prostate and other sexual organs, making them a candidate for treatment of frailty in older subjects. These agents have been shown to improve lean body mass in rodent models [106] and are currently in early clinical trials.

\section{Skeletal muscle and bone strength}

Maintenance of muscle mass and strength is critical for preservation of physical activity in older age and important for reducing the risks of falls and their most serious consequence, skeletal fractures. However, muscles exert powerful loads on the skeleton, and there is considerable interest in reducing fracture risk by using exercise strategies to increase or at least protect against loss of skeletal mass and strength with age [107]. The use of exercise strategies to strengthen the skeleton is based on the adaptive response of bone to varying mechanical loads as described by Frost, who proposed a homeostatic process governing the balance between bone remodeling, modeling, and repair as a function of varying strains imposed by inputs such as impacts and muscle forces [108]. The relationship between mechanical strains and skeletal tissue responses vary with the skeletal site, but the "set points" that trigger remodeling and modeling responses and thus the overall responsiveness of bone tissue to mechanical loading are modulated by the overall hormonal milieu.

A series of animal experiments have studied the relationships between mechanical strain and bone geometry and strength [109]. These studies have demonstrated the responsiveness of skeletal tissue to dynamic changes in mechanical loading and have shown the importance of the timing as well as the magnitudes of applied loads [110]. Recent studies have also indicated that mechanical loading has an effect on other properties of bone such as fatigue resistance and second moment of inertia that are significantly larger than effects on bone density and mass [111].

However, studies examining the effect of exercise regimes on bone in elderly subjects have indicated relatively modest effects. An excellent review of various exercise strategies on bone health has been published by Suominen [107]. Impact exercise such as walking and aerobic training has a pronounced benefit on overall health, and a small but positive effect on bone mass. However, from an anabolic point of view, resistive exercise seems to 
exert more favorable effects for potential improvements of bone strength. High-intensity and progressive trials of resistance exercise have shown significant effects on BMD at vertebral and hip sites. Studies in general have shown that the exercise must be continued to maintain the benefit that the additional gain is lost within a few years of the program if the protocol is not continued.

\section{Assessment of skeletal muscle using imaging}

Imaging offers the potential for an anatomic site-specific assessment of multiple targets related to skeletal muscle physiology. Imaging has an important role in research studies of sarcopenia etiology and response to intervention. The primary imaging target in skeletal muscle mass assessment is lean body mass assessment by DXA, which involves use of standard clinical bone densitometers to decompose nonbone tissue into lean and fat body mass components. Measurements may be obtained of total body lean and fat mass as well as regional measures in the central and appendicular skeleton. As this is an extremely widespread and well-known technology, which is commonly used in clinical studies in both bone and muscle research, we will refer the readers to several reviews that lay out the technical considerations for DXA soft tissue assessment [112-116].

CT imaging may be employed to quantify bulk characteristics of muscle and body composition that are highly related to muscle strength and to overall functional ability in the elderly. In particular, CT imaging is widely used to study muscle and fat in epidemiologic studies of body composition. Typically, acquisitions have included single cross sections at the $\mathrm{L} 1 / 2$ or $\mathrm{L} 4 / 5$ intervertebral space to image body fat or volumetric measurements obtained in the abdomen and in the thigh, usually relating to the midthigh or to a bony landmark $[23,83,88,117-121]$. As shown in Fig. 4, the key variables quantified include the total muscle CSA of the midthigh, the CSA values of the quadriceps and hamstrings, the total CSA of subcutaneous fat, and the attenuation coefficients of the total thigh muscle and the hamstrings and quadriceps separately. The CSA values of the total thigh muscle and quadriceps muscle are positively associated with increasing knee extensor strength [118]. The CSA declines with age, as does the muscle strength, and is smaller in females than in males [117-119]. Another property of great interest to the study of sarcopenia is the mean attenuation coefficient [23, 117-119], which is computed within all of the muscle regions after a threshold is applied to exclude depots of fat embedded within each muscle group. In elderly subjects, the mean attenuation coefficient, when calculated in this manner, has been shown histologically to correspond to fat accumulation within and between the muscle cells. The increasing fat infiltration into the muscle with aging may be an important, if not central, aspect of sarcopenia. Lower values of the mean thigh muscle attenuation coefficient correspond to increasing fattiness of muscle tissue. Decreasing thigh muscle attenuation is correlated to decreasing muscle strength, a relationship which is independent of the muscle CSA and the total amount of adipose tissue in the thigh.

Measures of CSA and muscle attenuation assessed at multiple skeletal sites are associated with indices of functional capacity in elderly adults, including chair stand and leg strength measurements which have been shown to be strongly predictive of falls [83, 88, 121]. Several studies based on the Health, Aging, and Body Composition Study, a large NIH-funded population study, have related measures of body composition derived by CT to indices of functional ability and quality of life in the independently living elderly. Visser et al. examined the relationship between measures of thigh composition and lower-extremity perfor-
Fig. $4 \mathrm{CT}$ acquisition through midthigh. Location of axial section is shown on localizer image at the left, with corresponding axial image in the middle and segmentation into distinct tissue compartments at the right. Green: subcutaneous fat. Olive: quadriceps muscle. Yellow: hamstrings muscle. Red: adductor muscles. Orange: sartorius muscle
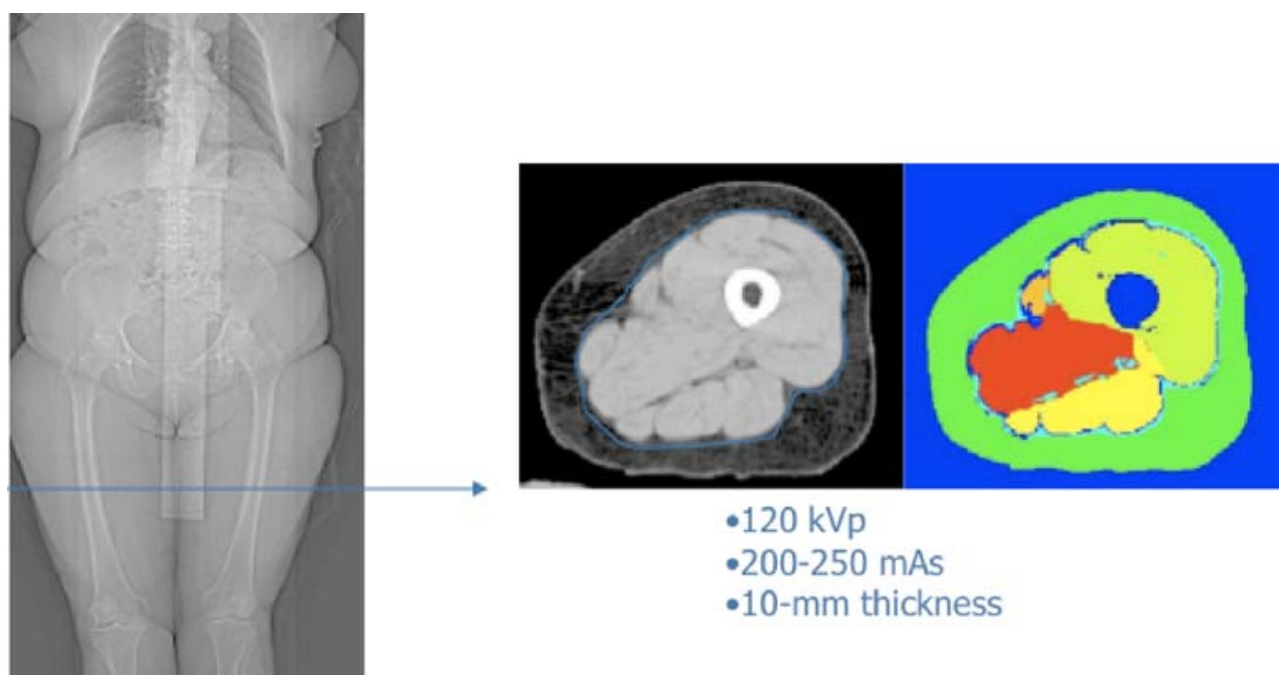
mance (LEP), assessed by two timed tests: a series of five chair stands without use of arms and a 6-m walk [83]. Reduced thigh CSA was associated with poorer LEP, as was reduced thigh muscle attenuation coefficient, even after the adjustment for muscle area. The attenuation coefficient of thigh muscle is not only related to current physical performance but is also related to incident functional decline. Analyzing longitudinal data from the Health $\mathrm{ABC}$ study, Visser et al. observed that low baseline values of thigh muscle attenuation predicted incident mobility limitation, defined as inability to walk one-quarter mile or climb ten steps [88]. Reduced thigh muscle attenuation coefficient is also associated with increased insulin resistance and the presence of metabolic syndrome in the elderly. Diabetes and other weight-related health conditions are associated with poor vision, musculoskeletal pain, and other conditions which are themselves indicators of increased fall risk [23].

\section{Magnetic resonance imaging}

MRI is an imaging technique that is based on using radio waves to excite protons in the presence of an external magnetic field. The resonance frequency at which protons maximally absorb the radioenergy is based on their local chemical environment. Because musculoskeletal tissues are rich in proton-containing molecules such as muscle proteins and lipids, MRI is an inherently powerful tool at depicting the anatomy of muscle tissues, particularly in the delineation of lean and adipose components of muscles. While some investigators have used 3D MRI acquisitions to determine lean tissue and intermuscular fat volumes in a range of applications, the true advantage of MRI is the ability to obtain spectroscopic data that can probe in vivo the ATP-generating functions within skeletal muscle and the storage of important nutrients such as lipid and glycogen.

Proton magnetic resonance spectroscopy $\left({ }^{1} \mathrm{H}-\mathrm{MRS}\right)$ is a technique that can differentiate lipids stored within adipocytes (extramyocellular lipid, EMCL) from intramyocellular lipid (IMCL) stored as droplets on the border of the myoplasm [122-127]. This differentiation is based on the variance in resonance frequency between protons contained in relatively cylindrical deposits of EMCL in adipocytes and protons contained in IMCL deposits which are spherical in shape. These resonances show up as different peaks on the proton spectrum of skeletal muscle (Fig. 5). Probing IMCL is of clinical importance because IMCL stores represent lipid which borders mitochondria and which represent an energy supply of free fatty acids for oxidation. IMCL intensity determined by ${ }^{1} \mathrm{H}-\mathrm{MRS}$ has been found to correlate with insulin resistance and obesity. The risk of insulin resistance is known to increase with age, and aging skeletal muscle is characterized by decreasing oxidative capacity that may lead to increased IMCL.

MRS may also be used to detect resonances of ${ }^{31} \mathrm{P}$ and ${ }^{13} \mathrm{C}$ nuclei contained in ATP, ADP inorganic phosphate, glycogen, and other chemical forms in skeletal muscle cells, shedding important light on muscle metabolism. ${ }^{31} \mathrm{P}$ MRS can be used to directly analyze relative abundances of ${ }^{31} \mathrm{P}$ contained in compounds of interest to energetics of skeletal muscle, including ATP, inorganic phosphate, and phosphocreatine [128-134]. Based on these primary measurements, it is also possible to use ${ }^{31} \mathrm{P}-\mathrm{MRS}$ to indirectly

\section{H-MRS at 3T}
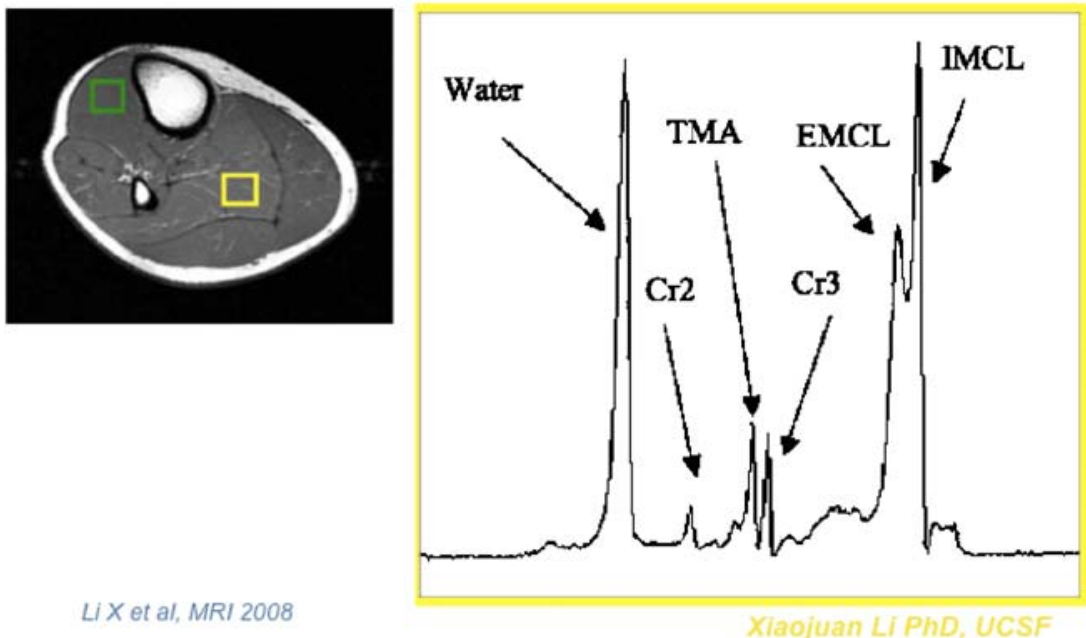

Fig. 5 MRI image of calf at the right, with green and yellow boxes indicating locations of spectroscopic acquisitions of the tibialis anterior and soleus muscles, respectively. Proton spectroscopy studies may be used to assess the relative amounts of intramyocellular and extramyocellular lipid. At the right, a proton spectrum corresponding to the soleus muscle shows ${ }^{1} \mathrm{H}$ resonances associated with creatinine (CR2 and $C R 3)$, water, extramyocellular lipid (EMCL), intramyocellular lipid (IMCL), and trimethylamines (TMA) 
estimate the intracellular $\mathrm{pH}$, as well as the free concentrations of ADP and $\mathrm{Mg}^{2+}$ ions. These measurements allow the technique to be used to estimate rates of ATP synthesis under ischemic (glycogenolytic) conditions or aerobic (oxidative) conditions. Other applications in skeletal muscle studies include estimates of the oxidative capacity of skeletal muscle, as well as the proton efflux and buffer capacity, which provide insight into the recovery of skeletal muscle from exercise.

The wide chemical shift of the ${ }^{13} \mathrm{C}$ resonance allows ${ }^{13} \mathrm{C}$-MRS to assess the relative abundances of a wide range of molecules related to glycogen synthesis and glycogenolysis [129, 135-143]. Using the natural abundance (1.1\%) of ${ }^{13} \mathrm{C}$, it is possible to detect resonances of ${ }^{13} \mathrm{C}$ in glycogen and triglyceride. This allows for estimates of glycogen turnover in skeletal muscle and for studies of insulin resistance and type 2 diabetes. By administration of ${ }^{13} \mathrm{C}$ glucose, it is possible to enrich ${ }^{13} \mathrm{C}$, allowing for more advanced determinations, such as examining glycogen synthesis rate and quantifying organelle and mitochondrial activity during the TCA cycle.

\section{Positron emission tomography}

Positron emission tomography (PET) is an imaging technique which is employed to image the biodistribution of a compound of interest labeled with a positron-emitting atom, for example an ${ }^{18} \mathrm{~F}$ or ${ }^{11} \mathrm{C}$. The most commonly employed PET imaging agent is ${ }^{18} \mathrm{~F}$-fluorodeoxyglucose (FDG), a glucose analog which is widely employed to study glucose metabolism across multiple tissue types. ${ }^{18} \mathrm{~F}$ FDG penetrates the cell membrane and is phosphorylated to FDG-6-phosphate and is no longer metabolized and thus is trapped within the cell. It builds up in the cell in proportion to the rate of glucose transport across the cell membrane and also in relation to the activities of hexokinase and glucose-6-phospotase within the cell. In skeletal muscle, FDG imaging has been employed to study glucose utilization. When used in conjunction with compartmental modeling, this approach has been employed to dissect the rate of glucose utilization in terms of the components of cell membrane transport and phosphorylative activity in insulin resistance associated with both obesity and diabetes [144, 145]. Another application of PET which is relevant to skeletal muscle is the use of ${ }^{11} \mathrm{C}$-methyl-methionine to estimate the rate of protein synthesis. This agent accumulates in skeletal muscle as ${ }^{11} \mathrm{C}$-labeled protein, and the use of this methylated agent has advantages over radiolabeled leucine in that the latter accumulates in the blood as ${ }^{11} \mathrm{C}$ labeled $\mathrm{CO}_{2}$. Fischmann and others have validated this technique against skeletal muscle biopsy and have used it to outline the rate of skeletal muscle protein synthesis in healthy young volunteers [146-148].

\section{Conclusions}

Sarcopenia represents a set of outcomes, including the primary outcomes of loss of skeletal muscle strength and endurance, and secondary outcomes which include loss of mobility and increased risk of disability and mortality. The bulk changes of muscle tissue which lead to these outcomes result from multiple processes occurring at the cellular level. These processes impact the performance of muscle by reducing the number of fibers and the performance of individual fibers. Age-related loss of motor neurons results in denervation of entire fibers, with a concomitant adaptive process that recruits some but not all of these of these fibers into surviving motor units. Changes in the hormonal and inflammatory milieu result in impairment of protein synthesis and increased protein degradation. Buildup or ROS may result in mitochondrial dysfunction which impairs muscle respiration and may result in fiber deterioration through loss of myonuclei. Alterations in expression of myogenic regulatory factors may impair the ability of aged muscle to repair damage. Fortunately, despite this wide range of deleterious age-related changes, there are promising interventions. Multiple studies have shown that resistive exercise among the elderly of both genders can result in substantial improvements in muscle strength and in overall functional status, where increases in muscle strength indices can exceed $50-100 \%$. For subjects who cannot tolerate or are unwilling to undertake exercise, pharmacologic interventions, such as GH or IGF-1 interventions, are under investigation. These have had mixed results, and newer approaches, such as myostatin inhibition and selective androgen receptor modulators, are also in the early stages of investigation. Noninvasive imaging approaches such as CT, MRI, and PET are showing promise as clinical tools that may yield important basic information regarding the mechanisms of sarcopenia and the modes of action of multiple interventions.

Conflicts of interest Thomas Lang has received an Independent Investigator Grant from Merck.

Open Access This article is distributed under the terms of the Creative Commons Attribution Noncommercial License which permits any noncommercial use, distribution, and reproduction in any medium, provided the original author(s) and source are credited.

\section{References}

1. Bureau UC (2006) In: Bureau UC (ed) US Census Bureau: international database. Table 94.

2. Greenlund LJ, Nair KS (2003) Sarcopenia-consequences, mechanisms, and potential therapies. Mech Ageing Dev 124:287-299

3. Brooks SV (2003) Current topics for teaching skeletal muscle physiology. Adv Physiol Educ 27:171-182 
4. Faulkner JA, Larkin LM, Claflin DR, Brooks SV (2007) Agerelated changes in the structure and function of skeletal muscles. Clin Exp Pharmacol Physiol 34:1091-1096

5. Brooks SV, Faulkner JA (1994) Skeletal muscle weakness in old age: underlying mechanisms. Med Sci Sports Exerc 26: 432-439

6. Celichowski J (2000) Mechanisms underlying the regulation of motor unit contraction in the skeletal muscle. J Physiol Pharmacol 51:17-33

7. Herzog W, Ait-Haddou R (2002) Considerations on muscle contraction. J Electromyogr Kinesiol 12:425-433

8. Larsson L, Ramamurthy B (2000) Aging-related changes in skeletal muscle. Mechanisms and interventions. Drugs Aging 17:303-316

9. Porter MM, Vandervoort AA, Lexell J (1995) Aging of human muscle: structure, function and adaptability. Scand J Med Sci Sports 5:129-142

10. Sakamoto K, Goodyear LJ (2002) Invited review: intracellular signaling in contracting skeletal muscle. J Appl Physiol 93:369-383

11. Westerblad H, Allen DG, Bruton JD, Andrade FH, Lannergren J (1998) Mechanisms underlying the reduction of isometric force in skeletal muscle fatigue. Acta Physiol Scand 162:253-260

12. Wick M (1999) Filament assembly properties of the sarcomeric myosin heavy chain. Poult Sci 78:735-742

13. Lexell J, Downham DY (1991) The occurrence of fibre-type grouping in healthy human muscle: a quantitative study of crosssections of whole vastus lateralis from men between 15 and 83 years. Acta Neuropathol 81:377-381

14. Lexell J, Downham DY, Larsson Y, Bruhn E, Morsing B (1995) Heavy-resistance training in older Scandinavian men and women: short- and long-term effects on arm and leg muscles. Scand J Med Sci Sports 5:329-341

15. Kostka T (2005) Quadriceps maximal power and optimal shortening velocity in 335 men aged $23-88$ years. Eur J Appl Physiol 95:140-145

16. Vandervoort AA (2002) Aging of the human neuromuscular system. Muscle Nerve 25:17-25

17. Doherty TJ (2003) Invited review: aging and sarcopenia. J Appl Physiol 95:1717-1727

18. Kirkland JL, Tchkonia T, Pirtskhalava T, Han J, Karagiannides I (2002) Adipogenesis and aging: does aging make fat go MAD? Exp Gerontol 37:757-767

19. Shefer G, Van de Mark DP, Richardson JB, Yablonka-Reuveni Z (2006) Satellite-cell pool size does matter: defining the myogenic potency of aging skeletal muscle. Dev Biol 294:50-66

20. Shefer G, Wleklinski-Lee M, Yablonka-Reuveni Z (2004) Skeletal muscle satellite cells can spontaneously enter an alternative mesenchymal pathway. J Cell Sci 117:5393-5404

21. Shefer G, Yablonka-Reuveni Z (2007) Reflections on lineage potential of skeletal muscle satellite cells: do they sometimes go MAD? Crit Rev Eukaryot Gene Expr 17:13-29

22. Dube J, Goodpaster BH (2006) Assessment of intramuscular triglycerides: contribution to metabolic abnormalities. Curr Opin Clin Nutr Metab Care 9:553-559

23. Goodpaster BH, Brown NF (2005) Skeletal muscle lipid and its association with insulin resistance: what is the role for exercise? Exerc Sport Sci Rev 33:150-154

24. Goodpaster BH, Kelley DE (2002) Skeletal muscle triglyceride: marker or mediator of obesity-induced insulin resistance in type 2 diabetes mellitus? Curr Diab Rep 2:216-222

25. Johnson NA, Stannard SR, Thompson MW (2004) Muscle triglyceride and glycogen in endurance exercise: implications for performance. Sports Med 34:151-164

26. Kelley DE (2002) Skeletal muscle triglycerides: an aspect of regional adiposity and insulin resistance. Ann N Y Acad Sci 967:135-145
27. Kelley DE, Goodpaster BH, Storlien L (2002) Muscle triglyceride and insulin resistance. Annu Rev Nutr 22:325-346

28. Kraegen EW, Cooney GJ (2008) Free fatty acids and skeletal muscle insulin resistance. Curr Opin Lipidol 19:235-241

29. Hamilton MT, Areiqat E, Hamilton DG, Bey L (2001) Plasma triglyceride metabolism in humans and rats during aging and physical inactivity. Int J Sport Nutr Exerc Metab 11(Suppl):S97104

30. Ramirez V, Ulfhake B (1992) Anatomy of dendrites in motoneurons supplying the intrinsic muscles of the foot sole in the aged cat: evidence for dendritic growth and neosynaptogenesis. J Comp Neurol 316:1-16

31. Kullberg S, Ramirez-Leon V, Johnson H, Ulfhake B (1998) Decreased axosomatic input to motoneurons and astrogliosis in the spinal cord of aged rats. J Gerontol Ser A Biol Sci Med Sci 53:B369-379

32. Gordon T, Hegedus J, Tam SL (2004) Adaptive and maladaptive motor axonal sprouting in aging and motoneuron disease. Neurol Res 26:174-185

33. Florini JR, Ewton DZ, Falen SL, Van Wyk JJ (1986) Biphasic concentration dependency of stimulation of myoblast differentiation by somatomedins. Am J Physiol 250:C771-778

34. Goldspink G, Yang SY (2004) The splicing of the IGF-I gene to yield different muscle growth factors. Adv Genet 52:23-49

35. Musaro A, McCullagh K, Paul A, Houghton L, Dobrowolny G, Molinaro M, Barton ER, Sweeney HL, Rosenthal N (2001) Localized Igf-1 transgene expression sustains hypertrophy and regeneration in senescent skeletal muscle. Nat Genet 27:195200

36. Petrella JK, Kim JS, Cross JM, Kosek DJ, Bamman MM (2006) Efficacy of myonuclear addition may explain differential myofiber growth among resistance-trained young and older men and women. Am J Physiol Endocrinol Metab 291:E937946

37. Firth SM, Baxter RC (2002) Cellular actions of the insulin-like growth factor binding proteins. Endocr Rev 23:824-854

38. Messi ML, Delbono O (2003) Target-derived trophic effect on skeletal muscle innervation in senescent mice. J Neurosci 23:1351-1359

39. Schertzer JD, van der Poel C, Shavlakadze T, Grounds MD, Lynch GS (2008) Muscle-specific overexpression of IGF-I improves $\mathrm{E}-\mathrm{C}$ coupling in skeletal muscle fibers from dystrophic mdx mice. Am J Physiol Cell Physiol 294:C161-168

40. Rasmussen BB, Fujita S, Wolfe RR, Mittendorfer B, Roy M, Rowe VL, Volpi E (2006) Insulin resistance of muscle protein metabolism in aging. FASEB J 20:768-769

41. Kandarian SC, Jackman RW (2006) Intracellular signaling during skeletal muscle atrophy. Muscle Nerve 33:155-165

42. Reid MB (2005) Response of the ubiquitin-proteasome pathway to changes in muscle activity. Am J Physiol Regul Integr Comp Physiol 288:R1423-1431

43. Giresi PG, Stevenson EJ, Theilhaber J, Koncarevic A, Parkington J, Fielding RA, Kandarian SC (2005) Identification of a molecular signature of sarcopenia. Physiol Genomics 21:253-263

44. Leeuwenburgh C (2003) Role of apoptosis in sarcopenia. J Gerontol Ser A Biol Sci Med Sci 58:999-1001

45. Hiona A, Leeuwenburgh C (2008) The role of mitochondrial DNA mutations in aging and sarcopenia: implications for the mitochondrial vicious cycle theory of aging. Exp Gerontol 43:24-33

46. Dirks AJ, Hofer T, Marzetti E, Pahor M, Leeuwenburgh C (2006) Mitochondrial DNA mutations, energy metabolism and apoptosis in aging muscle. Ageing Res Rev 5:179-195

47. Herbst A, Pak JW, McKenzie D, Bua E, Bassiouni M, Aiken JM (2007) Accumulation of mitochondrial DNA deletion mutations in aged muscle fibers: evidence for a causal role in muscle fiber loss. J Gerontol Ser A Biol Sci Med Sci 62:235-245 
48. Conboy IM, Conboy MJ, Smythe GM, Rando TA (2003) Notchmediated restoration of regenerative potential to aged muscle. Science 302:1575-1577

49. Verdijk LB, Koopman R, Schaart G, Meijer K, Savelberg HH, van Loon LJ (2007) Satellite cell content is specifically reduced in type II skeletal muscle fibers in the elderly. Am J Physiol Endocrinol Metab 292:E151-157

50. Dreyer HC, Blanco CE, Sattler FR, Schroeder ET, Wiswell RA (2006) Satellite cell numbers in young and older men 24 hours after eccentric exercise. Muscle Nerve 33:242-253

51. Gallegly JC, Turesky NA, Strotman BA, Gurley CM, Peterson CA, Dupont-Versteegden EE (2004) Satellite cell regulation of muscle mass is altered at old age. J Appl Physiol 97:1082-1090

52. Bigot A, Jacquemin V, Debacq-Chainiaux F, Butler-Browne GS, Toussaint O, Furling D, Mouly V (2008) Replicative aging down-regulates the myogenic regulatory factors in human myoblasts. Biol Cell 100:189-199

53. McCroskery S, Thomas M, Maxwell L, Sharma M, Kambadur R (2003) Myostatin negatively regulates satellite cell activation and self-renewal. J Cell Biol 162:1135-1147

54. Kawada S, Tachi C, Ishii N (2001) Content and localization of myostatin in mouse skeletal muscles during aging, mechanical unloading and reloading. J Muscle Res Cell Motil 22:627-633

55. Baumann AP, Ibebunjo C, Grasser WA, Paralkar VM (2003) Myostatin expression in age and denervation-induced skeletal muscle atrophy. J Musculoskelet Neuronal Interact 3:8-16

56. Welle S (2002) Cellular and molecular basis of age-related sarcopenia. Can J Appl Physiol 27:19-41

57. Raue U, Slivka D, Jemiolo B, Hollon C, Trappe S (2006) Myogenic gene expression at rest and after a bout of resistance exercise in young (18-30 yr) and old (80-89 yr) women. J Appl Physiol 101:53-59

58. Shadwick RE (1990) Elastic energy storage in tendons: mechanical differences related to function and age. J Appl Physiol 68:1033-1040

59. Nakagawa Y, Hayashi K, Yamamoto N, Nagashima K (1996) Age-related changes in biomechanical properties of the Achilles tendon in rabbits. Eur J Appl Physiol Occup Physiol 73:7-10

60. Blevins FT, Hecker AT, Bigler GT, Boland AL, Hayes WC (1994) The effects of donor age and strain rate on the biomechanical properties of bone-patellar tendon-bone allografts. Am J Sports Med 22:328-333

61. Flahiff CM, Brooks AT, Hollis JM, Vander Schilden JL, Nicholas RW (1995) Biomechanical analysis of patellar tendon allografts as a function of donor age. Am J Sports Med 23:354358

62. Narici MV, Maffulli N, Maganaris CN (2008) Ageing of human muscles and tendons. Disabil Rehabil 30:1548-1554

63. Maganaris CN, Paul JP (1999) In vivo human tendon mechanical properties. J Physiol 521(Pt 1):307-313

64. Reeves ND, Narici MV, Maganaris CN (2003) Strength training alters the viscoelastic properties of tendons in elderly humans. Muscle Nerve 28:74-81

65. Narici MV, Maganaris CN (2006) Adaptability of elderly human muscles and tendons to increased loading. J Anat 208:433-443

66. Nevitt MC, Cummings SR, Kidd S, Black D (1989) Risk factors for recurrent nonsyncopal falls. JAMA 261:2663-2668

67. Moreland JD, Richardson JA, Goldsmith CH, Clase CM (2004) Muscle weakness and falls in older adults: a systematic review and meta-analysis. J Am Geriatr Soc 52:1121-1129

68. Lanza IR, Towse TF, Caldwell GE, Wigmore DM, Kent-Braun JA (2003) Effects of age on human muscle torque, velocity, and power in two muscle groups. J Appl Physiol 95:2361-2369

69. Petrella JK, Kim JS, Tuggle SC, Hall SR, Bamman MM (2005) Age differences in knee extension power, contractile velocity, and fatigability. J Appl Physiol 98:211-220
70. Morse CI, Thom JM, Reeves ND, Birch KM, Narici MV (2005) In vivo physiological cross-sectional area and specific force are reduced in the gastrocnemius of elderly men. J Appl Physiol 99:1050-1055

71. Kubo K, Morimoto M, Komuro T, Tsunoda N, Kanehisa H, Fukunaga T (2007) Age-related differences in the properties of the plantar flexor muscles and tendons. Med Sci Sports Exerc 39:541547

72. Johnson ME, Mille ML, Martinez KM, Crombie G, Rogers MW (2004) Age-related changes in hip abductor and adductor joint torques. Arch Phys Med Rehabil 85:593-597

73. Dean JC, Kuo AD, Alexander NB (2004) Age-related changes in maximal hip strength and movement speed. J Gerontol Ser A Biol Sci Med Sci 59:286-292

74. Larsson L, Grimby G, Karlsson J (1979) Muscle strength and speed of movement in relation to age and muscle morphology. J Appl Physiol 46:451-456

75. Murray MP, Duthie EH Jr, Gambert SR, Sepic SB, Mollinger LA (1985) Age-related differences in knee muscle strength in normal women. J Gerontol 40:275-280

76. Murray MP, Gardner GM, Mollinger LA, Sepic SB (1980) Strength of isometric and isokinetic contractions: knee muscles of men aged 20 to 86 . Phys Ther 60:412-419

77. Young A, Stokes M, Crowe M (1984) Size and strength of the quadriceps muscles of old and young women. Eur J Clin Invest $14: 282-287$

78. Young A, Stokes M, Crowe M (1985) The size and strength of the quadriceps muscles of old and young men. Clin Physiol 5:145-154

79. Hughes VA, Frontera WR, Wood M, Evans WJ, Dallal GE, Roubenoff R, Fiatarone Singh MA (2001) Longitudinal muscle strength changes in older adults: influence of muscle mass, physical activity, and health. J Gerontol Ser A Biol Sci Med Sci 56:B209-217

80. Aniansson A, Hedberg M, Henning GB, Grimby G (1986) Muscle morphology, enzymatic activity, and muscle strength in elderly men: a follow-up study. Muscle Nerve 9:585-591

81. Greig CA, Botella J, Young A (1993) The quadriceps strength of healthy elderly people remeasured after eight years. Muscle Nerve 16:6-10

82. Overend TJ, Cunningham DA, Paterson DH, Lefcoe MS (1992) Thigh composition in young and elderly men determined by computed tomography. Clin Physiol 12:629-640

83. Visser M, Kritchevsky S, Goodpaster B, Newman A, Nevitt M, Stamm E, Harris T (2002) Leg muscle mass and composition in relation to lower extremity performance in men and women aged 70-79: the health aging and body composition study. J Am Geriat Soc 50:897-905

84. Thelen DG, Muriuki M, James J, Schultz AB, Ashton-Miller JA, Alexander NB (2000) Muscle activities used by young and old adults when stepping to regain balance during a forward fall. $\mathrm{J}$ Electromyogr Kinesiol 10:93-101

85. Thelen DG, Wojcik LA, Schultz AB, Ashton-Miller JA, Alexander NB (1997) Age differences in using a rapid step to regain balance during a forward fall. J Gerontol Ser A Biol Sci Med Sci 52:M8-13

86. Wojcik LA, Thelen DG, Schultz AB, Ashton-Miller JA, Alexander NB (1999) Age and gender differences in singlestep recovery from a forward fall. J Gerontol Ser A Biol Sci Med Sci 54:M44-50

87. Wojcik LA, Thelen DG, Schultz AB, Ashton-Miller JA, Alexander NB (2001) Age and gender differences in peak lower extremity joint torques and ranges of motion used during singlestep balance recovery from a forward fall. J Biomech 34:67-73

88. Visser M, Goodpaster BH, Kritchevsky SB, Newman AB, Nevitt M, Rubin SM, Simonsick EM, Harris TB (2005) Muscle mass, 
muscle strength, and muscle fat infiltration as predictors of incident mobility limitations in well-functioning older persons. J Gerontol Ser A Biol Sci Med Sci 60:324-333

89. Lang TF, Cauley J, Tylavsky F, Bauer D, Cummings S, Harris TB (2009) Computed tomography measurements of thigh muscle cross-sectional area and attenuation coefficient predict hip fracture: The Health, Aging and Body Composition Study. J Bone Miner Res doi:10.1359/jbmr.090807

90. Frontera WR, Meredith CN, O'Reilly KP, Knuttgen HG, Evans WJ (1988) Strength conditioning in older men: skeletal muscle hypertrophy and improved function. J Appl Physiol 64:1038-1044

91. Charette SL, McEvoy L, Pyka G, Snow-Harter C, Guido D, Wiswell RA, Marcus R (1991) Muscle hypertrophy response to resistance training in older women. J Appl Physiol 70:19121916

92. Henwood TR, Taaffe DR (2008) Detraining and retraining in older adults following long-term muscle power or muscle strength specific training. J Gerontol A Biol Sci Med Sci 63:751-758

93. Fiatarone MA, Marks EC, Ryan ND, Meredith CN, Lipsitz LA, Evans WJ (1990) High-intensity strength training in nonagenarians. Effects on skeletal muscle. JAMA 263:3029-3034

94. Fiatarone MA, O’Neill EF, Ryan ND, Clements KM, Solares GR, Nelson ME, Roberts SB, Kehayias JJ, Lipsitz LA, Evans WJ (1994) Exercise training and nutritional supplementation for physical frailty in very elderly people. N Engl J Med 330:1769-1775

95. Morley JE, Haren MT, Kim MJ, Kevorkian R, Perry HM 3rd (2005) Testosterone, aging and quality of life. J Endocrinol Invest 28:76-80

96. Borst SE (2004) Interventions for sarcopenia and muscle weakness in older people. Age Ageing 33:548-555

97. Wang C, Swerdloff RS, Iranmanesh A, Dobs A, Snyder PJ, Cunningham G, Matsumoto AM, Weber T, Berman N (2000) Transdermal testosterone gel improves sexual function, mood, muscle strength, and body composition parameters in hypogonadal men. J Clin Endocrinol Metab 85:2839-2853

98. Bhasin S, Storer TW, Berman N, Yarasheski KE, Clevenger B, Phillips J, Lee WP, Bunnell TJ, Casaburi R (1997) Testosterone replacement increases fat-free mass and muscle size in hypogonadal men. J Clin Endocrinol Metab 82:407-413

99. Brodsky IG, Balagopal P, Nair KS (1996) Effects of testosterone replacement on muscle mass and muscle protein synthesis in hypogonadal men - a clinical research center study. J Clin Endocrinol Metab 81:3469-3475

100. Fuh VL, Bach MA (1998) Growth hormone secretagogues: mechanism of action and use in aging. Growth Horm IGF Res $8: 13-20$

101. Giovannini S, Marzetti E, Borst SE, Leeuwenburgh C (2008) Modulation of GH/IGF-1 axis: potential strategies to counteract sarcopenia in older adults. Mech Ageing Dev 129:593-601

102. Boonen S, Rosen C, Bouillon R, Sommer A, McKay M, Rosen D, Adams S, Broos P, Lenaerts J, Raus J, Vanderschueren D, Geusens P (2002) Musculoskeletal effects of the recombinant human IGF-I/IGF binding protein-3 complex in osteoporotic patients with proximal femoral fracture: a doubleblind, placebo-controlled pilot study. J Clin Endocrinol Metab 87:1593-1599

103. Bradley L, Yaworsky PJ, Walsh FS (2008) Myostatin as a therapeutic target for musculoskeletal disease. Cell Mol Life Sci 65:2119-2124

104. Tobin JF, Celeste AJ (2005) Myostatin, a negative regulator of muscle mass: implications for muscle degenerative diseases. Curr Opin Pharmacol 5:328-332

105. Walsh FS, Celeste AJ (2005) Myostatin: a modulator of skeletalmuscle stem cells. Biochem Soc Trans 33:1513-1517
106. Gao W, Reiser PJ, Coss CC, Phelps MA, Kearbey JD, Miller DD, Dalton JT (2005) Selective androgen receptor modulator treatment improves muscle strength and body composition and prevents bone loss in orchidectomized rats. Endocrinology 146:4887-4897

107. Suominen H (2006) Muscle training for bone strength. Aging Clin Exp Res 18:85-93

108. Frost HM (1987) Bone "mass" and the "mechanostat": a proposal. Anat Rec 219:1-9

109. Bass SL, Saxon L, Daly RM, Turner CH, Robling AG, Seeman E, Stuckey S (2002) The effect of mechanical loading on the size and shape of bone in pre-, peri-, and postpubertal girls: a study in tennis players. J Bone Miner Res 17:2274-2280

110. Robling AG, Hinant FM, Burr DB, Turner CH (2002) Shorter, more frequent mechanical loading sessions enhance bone mass. Med Sci Sports Exerc 34:196-202

111. Warden SJ, Hurst JA, Sanders MS, Turner CH, Burr DB, Li J (2005) Bone adaptation to a mechanical loading program significantly increases skeletal fatigue resistance. J Bone Miner Res 20:809-816

112. Albanese CV, Diessel E, Genant HK (2003) Clinical applications of body composition measurements using DXA. J Clin Densitom 6:75-85

113. Pichard C, Genton L, Jolliet P (2000) Measuring body composition: a landmark of quality control for nutritional support services. Curr Opin Clin Nutr Metab Care 3:281-284

114. Plank LD (2005) Dual-energy X-ray absorptiometry and body composition. Curr Opin Clin Nutr Metab Care 8:305-309

115. Wells JC, Fewtrell MS (2006) Measuring body composition. Arch Dis Child 91:612-617

116. Woodrow G (2007) Body composition analysis techniques in adult and pediatric patients: how reliable are they? How useful are they clinically? Perit Dial Int 27(Suppl 2):S245-249

117. Goodpaster BH, Carlson CL, Visser M, Kelley DE, Scherzinger A, Harris TB, Stamm E, Newman AB (2001) Attenuation of skeletal muscle and strength in the elderly: the health $\mathrm{ABC}$ study. J Appl Physiol 90:2157-2165

118. Goodpaster BH, Kelley DE, Thaete FL, He J, Ross R (2000) Skeletal muscle attenuation determined by computed tomography is associated with skeletal muscle lipid content. J Appl Physiol 89:104-110

119. Goodpaster BH, Park SW, Harris TB, Kritchevsky SB, Nevitt M, Schwartz AV, Simonsick EM, Tylavsky FA, Visser M, Newman $\mathrm{AB}$ (2006) The loss of skeletal muscle strength, mass, and quality in older adults: the health, aging and body composition study. J Gerontol Ser A Biol Sci Med Sci 61:1059-1064

120. Taaffe DR, Henwood TR, Nalls MA, Walker DG, Lang TF, Harris TB (2008) Alterations in muscle attenuation following detraining and retraining in resistance-trained older adults. Gerontology 55:217-223

121. Visser M, Deeg DJ, Lips P, Harris TB, Bouter LM (2000) Skeletal muscle mass and muscle strength in relation to lowerextremity performance in older men and women. J Am Geriatr Soc 48:381-386

122. Boesch C, Machann J, Vermathen P, Schick F (2006) Role of proton MR for the study of muscle lipid metabolism. NMR Biomed 19:968-988

123. Machann J, Stefan N, Schick F (2008) (1)H MR spectroscopy of skeletal muscle, liver and bone marrow. Eur J Radiol 67:275-284

124. Torriani M (2007) Measuring muscle lipids with 1H-MR spectroscopy. Skeletal Radiol 36:607-608

125. Weis J, Courivaud F, Hansen MS, Johansson L, Ribe LR, Ahlstrom H (2005) Lipid content in the musculature of the lower leg: evaluation with high-resolution spectroscopic imaging. Magn Reson Med 54:152-158 
126. Weis J, Johansson L, Ortiz-Nieto F, Ahlstrom H (2008) Assessment of lipids in skeletal muscle by high-resolution spectroscopic imaging using fat as the internal standard: comparison with water referenced spectroscopy. Magn Reson Med 59:1259-1265

127. Wells GD, Noseworthy MD, Hamilton J, Tarnopolski M, Tein I (2008) Skeletal muscle metabolic dysfunction in obesity and metabolic syndrome. Can J Neurol Sci 35:31-40

128. Bendahan D, Mattei JP, Guis S, Kozak-Ribbens G, Cozzone PJ (2006) Non-invasive investigation of muscle function using 31P magnetic resonance spectroscopy and $1 \mathrm{H}$ MR imaging. Rev Neurol (Paris) 162:467-484

129. Boesch C (2007) Musculoskeletal spectroscopy. J Magn Reson Imaging 25:321-338

130. Brosseau OE, Mahdjoub R, Seurin MJ, Thiriet P, Gozal D, Briguet A (2003) Kinetics of anaerobic metabolism in human skeletal muscle: influence of repetitive high-intensity exercise on sedentary dominant and non-dominant forearm. A 31P NMR study. Biochimie 85:885-890

131. Lanza IR, Befroy DE, Kent-Braun JA (2005) Age-related changes in ATP-producing pathways in human skeletal muscle in vivo. J Appl Physiol 99:1736-1744

132. Lanza IR, Wigmore DM, Befroy DE, Kent-Braun JA (2006) In vivo ATP production during free-flow and ischaemic muscle contractions in humans. J Physiol 577:353-367

133. Mairiang E, Hanpanich P, Sriboonlue P (2004) In vivo 31PMRS assessment of muscle-pH, cytosolic-[Mg2+] and phosphorylation potential after supplementing hypokaliuric renal stone patients with potassium and magnesium salts. Magn Reson Imaging 22:715-719

134. Taylor JH, Beilman GJ, Conroy MJ, Mulier KE, Myers D, Gruessner A, Hammer BE (2004) Tissue energetics as measured by nuclear magnetic resonance spectroscopy during hemorrhagic shock. Shock 21:58-64

135. Delmas-Beauvieux MC, Quesson B, Thiaudiere E, Gallis JL, Canioni $\mathrm{P}$, Gin $\mathrm{H}(1999){ }^{13} \mathrm{C}$ nuclear magnetic resonance study of glycogen resynthesis in muscle after glycogen-depleting exercise in healthy men receiving an infusion of lipid emulsion. Diabetes 48:327-333

136. Hunter GR, Newcomer BR, Larson-Meyer DE, Bamman MM, Weinsier RL (2001) Muscle metabolic economy is inversely related to exercise intensity and type II myofiber distribution. Muscle Nerve 24:654-661

137. Krssak M, Petersen KF, Bergeron R, Price T, Laurent D, Rothman DL, Roden M, Shulman GI (2000) Intramuscular glycogen and intramyocellular lipid utilization during prolonged exercise and recovery in man: a ${ }^{13} \mathrm{C}$ and ${ }^{1} \mathrm{H}$ nuclear magnetic resonance spectroscopy study. J Clin Endocrinol Metab 85:748-754

138. Meynial-Denis D, Miri A, Bielicki G, Mignon M, Renou JP, Grizard J (2005) Insulin-dependent glycogen synthesis is delayed in onset in the skeletal muscle of food-deprived aged rats. J Nutr Biochem 16:150-154

139. Rico-Sanz J, Zehnder M, Buchli R, Dambach M, Boutellier U (1999) Muscle glycogen degradation during simulation of a fatiguing soccer match in elite soccer players examined noninvasively by ${ }^{13} \mathrm{C}$-MRS. Med Sci Sports Exerc 31:1587-1593

140. Rico-Sanz J, Zehnder M, Buchli R, Kuhne G, Boutellier U (1999) Noninvasive measurement of muscle high-energy phosphates and glycogen concentrations in elite soccer players by ${ }^{31} \mathrm{P}$ - and ${ }^{13} \mathrm{C}-\mathrm{MRS}$. Med Sci Sports Exerc 31:1580-1586

141. Rotman S, Slotboom J, Kreis R, Boesch C, Jequier E (2000) Muscle glycogen recovery after exercise measured by ${ }^{13} \mathrm{C}$ - magnetic resonance spectroscopy in humans: effect of nutritional solutions. MAGMA 11:114-121

142. Shulman RG, Rothman DL (2001) ${ }^{13} \mathrm{C}$ NMR of intermediary metabolism: implications for systemic physiology. Annu Rev Physiol 63:15-48

143. Van Den Bergh AJ, Tack CJ, Van Den Boogert HJ, Vervoort G, Smits P, Heerschap A (2000) Assessment of human muscle glycogen synthesis and total glucose content by in vivo ${ }^{13} \mathrm{C}$ MRS. Eur J Clin Invest 30:122-128

144. Bertoldo A, Pencek RR, Azuma K, Price JC, Kelley C, Cobelli C, Kelley DE (2006) Interactions between delivery, transport, and phosphorylation of glucose in governing uptake into human skeletal muscle. Diabetes 55:3028-3037

145. Bertoldo A, Price J, Mathis C, Mason S, Holt D, Kelley C, Cobelli C, Kelley DE (2005) Quantitative assessment of glucose transport in human skeletal muscle: dynamic positron emission tomography imaging of [ $O$-methyl-11C]3-O-methyl-D-glucose. J Clin Endocrinol Metab 90:1752-1759

146. Carter EA, Yu YM, Alpert NM, Bonab AA, Tompkins RG, Fischman AJ (1999) Measurement of muscle protein synthesis by positron emission tomography with L-[methyl-11C]methionine: effects of transamination and transmethylation. J Trauma 47:341-345

147. Fischman AJ, Yu YM, Livni E, Babich JW, Young VR, Alpert NM, Tompkins RG (1998) Muscle protein synthesis by positronemission tomography with L-[methyl-11C]methionine in adult humans. Proc Natl Acad Sci U S A 95:12793-12798

148. Hsu H, Yu YM, Babich JW, Burke JF, Livni E, Tompkins RG, Young VR, Alpert NM, Fischman AJ (1996) Measurement of muscle protein synthesis by positron emission tomography with L-[methyl-11C]methionine. Proc Natl Acad Sci U S A 93:18411846

149. Solerte SB, Gazzaruso C, Bonacasa R, Rondanelli M, Zamboni M, Basso C, Locatelli E, Schifino N, Giustina A, Fioravanti M (2008) Nutritional supplements with oral amino acid mixtures increases whole-body lean mass and insulin sensitivity in elderly subjects with sarcopenia. Am J Cardiol 101:69E-77E

150. Trappe S, Williamson D, Godard M, Porter D, Rowden G, Costill D (2000) Effect of resistance training on single muscle fiber contractile function in older men. J Appl Physiol 89:143152

151. Trappe S, Godard M, Gallagher P, Carroll C, Rowden G, Porter D (2001) Resistance training improves single muscle fiber contractile function in older women. Am J Physiol Cell Physiol 281:C398-406

152. Slivka D, Raue U, Hollon C, Minchev K, Trappe S (2008) Single muscle fiber adaptations to resistance training in old $(>80 \mathrm{yr})$ men: evidence for limited skeletal muscle plasticity. Am J Physiol Regul Integr Comp Physiol 295:R273-280

153. Kryger AI, Andersen JL (2007) Resistance training in the oldest old: consequences for muscle strength, fiber types, fiber size, and MHC isoforms. Scand J Med Sci Sports 17: 422-430

154. Frontera WR, Hughes VA, Krivickas LS, Kim SK, Foldvari M, Roubenoff R (2003) Strength training in older women: early and late changes in whole muscle and single cells. Muscle Nerve 28:601-608

155. Wittert GA, Chapman IM, Haren MT, Mackintosh S, Coates P, Morley JE (2003) Oral testosterone supplementation increases muscle and decreases fat mass in healthy elderly males with lownormal gonadal status. J Gerontol Ser A Biol Sci Med Sci $58: 618-625$ 